\title{
Inside and outside bark volume models for jack pine (Pinus banksiana) and black spruce (Picea mariana) plantations in Ontario, Canada
}

\author{
by Mahadev Sharma ${ }^{1}$
}

\begin{abstract}
Accurate estimates of tree stemwood volume are a fundamental requirement for sustainable forest management. As jack pine (Pinus banksiana Lamb.) and black spruce (Picea mariana Mill. BSP) are the primary species harvested in boreal Ontario, Canada, inside and outside bark tree volume models were developed for these species grown in plantations. Data used in this study came from stem analysis of 1135 jack pine and 1189 black spruce trees sampled from 25 evenaged monospecific plantations in the boreal forest region of northern Ontario. Three alternative model forms were considered and the final model was selected based on fit statistics, predictive accuracy, and logical consistency. A tree volume model is considered logically consistent if it produces volume estimates greater than zero and, regardless of tree size, outside bark tree volume exceeds inside bark volume.
\end{abstract}

A nonlinear mixed-effects modelling approach was used to address the three-level (plantation, plot, and tree) hierarchical error structure. However, plantation and plot scale random effects were not significant in the regression. A weighted (power function) was used to address heteroscedasticity in the data. The modified form of the dimensionally compatible volume model outperformed the other two models in terms of fit statistics, predictive accuracy, and logical consistency. Therefore, this model was selected as the inside and outside bark volume model for both species.

Key words: Nonlinear mixed-effects models, boreal tree species, and logical consistency

\section{RÉSUMÉ}

Il faut de bonnes estimations sur volume de bois par arbre pour faire de l'aménagement forestier durable. Le pin gris (Pinus banksiana Lamb.) et l'épinette noire (Picea mariana Mill. BSP) sont les principales essences récoltées dans la région boréale de l'Ontario, au Canada ; c'est donc pour ces essences qu'il fut décidé de modéliser le volume de bois avec et sans écorce pour des arbres cultivés en plantations. Les données utilisées dans cette étude proviennent d'analyses de tiges de 1135 pins gris et de 1189 épinettes noires échantillonnées dans 25 plantations équiennes et monospécifiques dans la région de la forêt boréale du nord de l'Ontario. On a comparé trois formes de modèle pour n'en retenir qu'un sur la base des statistiques d'ajustement, de la précision des estimations et de la cohérence logique. Un modèle est considéré comme logiquement cohérent s'il produit des estimations de volume supérieures à zéro et si le volume extérieur avec écorce de l’arbre dépasse le volume sous écorce, peu importe la taille de l’arbre.

Le modèle retenu est un modèle non linéaire à effets mixtes qui tient compte de la structure d'erreur hiérarchique à trois niveaux (plantation, parcelle et arbre). Les effets aléatoires à l'échelle des plantations et des parcelles n'ont pas eu d'effets significatifs dans la régression. Pour la pondération, on a eu recours à une fonction de puissance afin de tenir compte de l'hétéroscédasticité des données. La forme modifiée du modèle de volume, compatible sur le plan dimensionnel, s'est avérée supérieure aux deux autres modèles sur la base des statistiques d'ajustement, de la précision prédictive et de la cohérence logique. Par conséquent, c'est ce modèle qui a été retenu pour modéliser le volume avec et sans écorce pour les deux essences.

Mots-clés : modèles non linéaires à effets mixtes, essences d’arbres boréales, cohérence logique

\footnotetext{
${ }^{1}$ Ministry of Natural Resources and Forestry, Ontario Forest Research Institute, 1235 Queen St East, Sault Ste Marie, ON P6A 2E5; email: mahadev.sharma@ontario.ca
} 


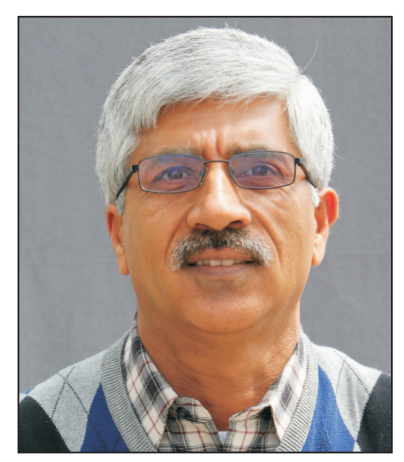

Mahadev Sharma

\section{Introduction}

Accurate estimates of tree volume (i.e., stem-wood volume) are crucial for developing forest management plans and calculating sustainable wood supplies. Tree volumes are estimated using volume models or taper models. Estimates from volume models are typically based on two easily measured dimensions, diameter outside bark at breast height $(\mathrm{DBH} ; 1.3 \mathrm{~m}$ above ground) and total height from ground to tip. The same dimensional measurements are used in taper models but volume estimates are obtained by integrating the taper over the tree height. While taper models provide more information about tree shape and may be used to obtain estimated volumes for any portion of the stem, volume models are simpler to use if only the entire stem volume is of interest. Further, volume estimates may be given as inside or outside bark depending on the intended use of this information, where inside bark volumes are less than outside bark volumes for a given tree.

Volume estimates can be summed to obtain plot volume estimates, given the $\mathrm{DBH}$ and height of each tree, to obtain stand volume per hectare estimates, as well as to document changes over time on permanent sample plots. Collectively, these estimates are critical for current and future growing stock estimates for stand or landscape-scale planning. Accurate estimates of volume are also vital for calculating tree and stand biomass and carbon stocks. Tree biomass can be calculated by multiplying tree volume by wood density and carbon content by taking a fraction of the biomass (Schlesinger 1991).

Since form is less parabolic in plantation-grown trees relative to those growing in a naturally regenerated stand for a given diameter at breast height and total tree height (Sharma and Parton 2009), a plantation-grown tree will have less volume. Therefore, wood volumes of plantation-grown trees are likely to be overestimated if calculated using models developed from data from natural stands. Using these volume estimates in forest management planning could jeopardize calculations of sustainable wood supply. Having volume models that are specific to plantations and to natural stands will help ensure more accurate estimates of volume and wood supply.

The province of Ontario has some 71.1 million ha of forests, amounting to about $17 \%$ of Canada's and $2 \%$ of the world's forests; almost half of this area is managed for timber. Of this managed area, black spruce dominates 37\% and jack pine $12 \%$. Under the Crown Forest Sustainability Act (Statutes of Ontario 1995), before harvesting can occur, each of the province's 41 management units must have an approved management plan based on a sustainable supply of wood into the future. On average, between 2009 and 2013, 125000 hectares of forests were harvested annually (OMNRF 2016), and more than $70 \%$ of the harvested volume was jack pine and black spruce. In general, harvested areas are regen- erated by planting the same species as removed during harvesting. Taper models for plantation grown jack pine (Pinus banksiana Lamb.) and black spruce (Picea mariana (Mill.) BSP) were developed by Sharma and Parton (2009). However, volume models using data from plantations in Ontario are not available.

The objective of this study was to develop inside and outside bark volume models for plantation grown jack pine and black spruce. For this purpose, three volume models-a modified form of dimensionally compatible, a combined variable, and a modified combined variable-were fitted to the data and compared on goodness of fit statistics, predictive accuracy, and logical consistency. A tree volume model is logically consistent if its volume estimates are greater than zero and the outside bark tree volume exceeds inside bark volume regardless of tree size. Given the hierarchical nature of the data, (trees nested within plots and plots nested within sites), a mixed-effects modelling approach was used to fit these models. The model resulting in the best fit, predictive accuracy, and logical consistency was selected as the most appropriate model for plantation-grown jack pine and black spruce.

\section{Methods \\ Data}

Stem analysis data used in this study represent plantationgrown jack pine and black spruce. Twenty-five even-aged, monospecific plantations of each species were sampled from throughout the Canadian boreal forest region of northern Ontario (Fig. 1). Detailed information about these plantations, including tree and stand characteristics, can be found in Sharma and Parton (2009). Within each plantation, three circular temporary sample plots (TSPs) were established, using a minimum plot size of $400 \mathrm{~m}^{2}$ and increasing this to obtain approximately 80 target species for each plot.

Since these plantations were at least 30-years-old, natural seedlings had established in some plots, resulting in a mixture of species. Therefore, all live trees in the plot, regardless of species, were measured for diameter to calculate stand characteristics (total basal area ha $\mathrm{h}^{-1}$ and trees ha ${ }^{-1}$ ). All targeted species were sequentially numbered and the cumulative basal area for the plot was determined for each species. Total cumulative basal area of target species was divided into five basal area ha ${ }^{-1}$ classes for each plot. Three trees that were regarded as planted and did not exhibit any visible deformities, such as forks, major stem injuries, or dead or broken tops, were randomly selected from each basal area class for destructive sampling. In addition, the largest diameter tree was selected from most of the plots. Thus, a minimum of 15 trees were sampled from each TSP, resulting in 45 to 48 trees per species from each plantation. In all, 1135 jack pine and 1189 black spruce trees were sampled from 25 plantations across northern Ontario.

From each sample tree, disks were cut at $0.15,0.5,0.9$ and $1.3 \mathrm{~m}$ (breast height). The remaining stem was divided into one of two sampling schemes: $5 \%$ and $10 \%$ of the relative height. For the $5 \%$, the remaining height was divided by 20 and disks were cut at intervals from breast height; similarly, for the $10 \%$ of relative height sampling scheme, the remaining height was divided by 10 and disks were cut at the relative 


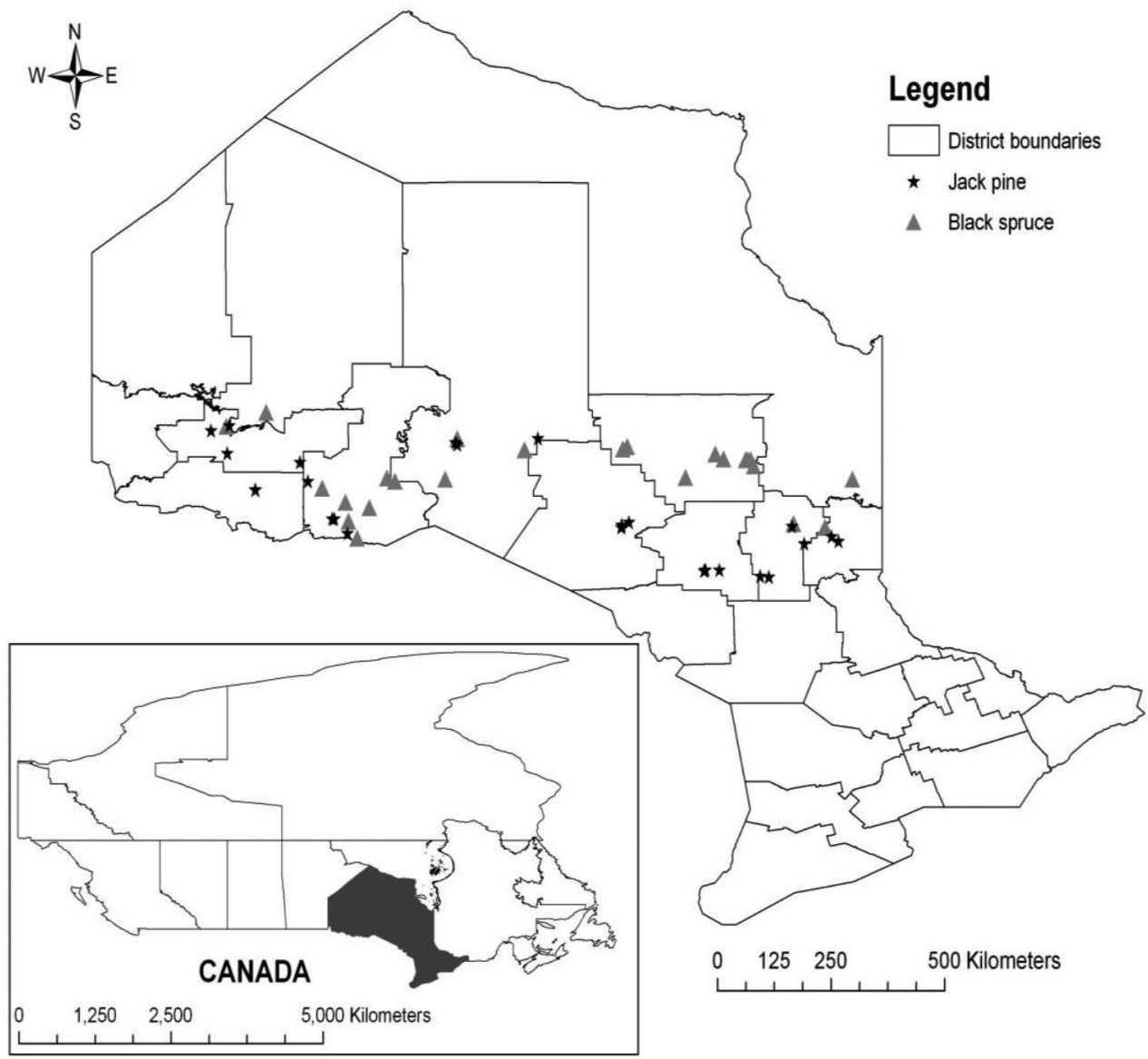

Fig. 1 Distribution of jack pine and black spruce plantations sites sampled across northern Ontario, Canada.

interval. Twenty percent of sampled trees from each plantation were selected for disk sampling at 5\% of relative height; the remainder were cut using the $10 \%$ of relative height. For each tree, this resulted in 23 disks for the $5 \%$ and 13 for the $10 \%$ sampling. Outside bark diameters were measured at each stem height where the disks were cut.

Each sampled tree and disk were given a unique code. All disks from a tree were placed in a breathable bag, transported and stored at $-10^{\circ} \mathrm{C}$ until 24 hours prior to preparation. Geometric mean radius (inside bark) was calculated from diameters obtained from the major $\left(\mathrm{r}_{1}\right)$ and minor $\left(\mathrm{r}_{2}\right)$ axes on each disk (i.e., $\left.r=\left(r_{1} \cdot r_{2}\right)^{0.5}\right)$. This resulted in 18002 observations for jack pine and 18852 for black spruce.

For each section between two consecutive disks, inside and outside bark volumes were calculated using Smalian's formula (Avery and Burkhart 2002). The sections below the first disk (butt) and above the last disk (top) were assumed to be a cylinder and a cone, respectively, and volumes were calculated accordingly. The inside and outside bark section volumes from individual trees were accumulated to obtain total inside and outside bark volumes for each tree for both species. Only 403 jack pine outside bark diameters were measured. Therefore, outside bark volumes were calculated for only those trees. Tree summary statistics are given in Table 1.

\section{Volume models}

A tree acquires some volume before it reaches breast height. Therefore, estimated volumes for the inside and outside bark should be positive and greater than zero even when DBH is close to zero. Similarly, the outside bark volume estimates should exceed those for inside bark regardless of tree size. These properties are required for a logically consistent tree volume model. In developing the volume models in this study, three base models were selected and analyzed.

The first considered was the dimensionally compatible volume model developed to be used with any system of units (Sharma and Oderwald (2001). It provided good fit statistics ( $\mathrm{R}^{2}$ and MSE) and predictive accuracy for loblolly pine (Pinus taeda L.) grown in natural stands (Sharma and Oderwald 2001, Sharma et al. 2002). The model is expressed as:

$$
V=\beta D^{\gamma} H^{3-\gamma}+\varepsilon
$$


Table 1. Summary statistics for characteristics of plantation jack pine and black spruce from boreal Ontario measured for use in this study. (DBH = diameter at breast height, height = total height, volume IB = volume inside bark, volume $\mathrm{OB}$ = volume outside bark)

\begin{tabular}{lccccc}
\hline $\begin{array}{l}\text { Species/ } \\
\text { variable }\end{array}$ & $\begin{array}{c}\text { Number } \\
\text { of trees }\end{array}$ & Mean & Std dev & Minimum & Maximum \\
\hline Jack pine & & & & & \\
DBH $(\mathrm{cm})$ & 1135 & 17.34 & 4.46 & 6.10 & 34.30 \\
Height $(\mathrm{m})$ & 1135 & 5.47 & 2.54 & 7.93 & 23.17 \\
Volume IB $\left(\mathrm{m}^{3}\right)$ & 1135 & 0.1820 & 0.1092 & 0.0114 & 0.7690 \\
Volume OB $\left(\mathrm{m}^{3}\right)$ & 403 & 0.2188 & 0.1198 & 0.0426 & 0.8048 \\
& & & & & \\
Black spruce & 1189 & 13.35 & 3.70 & 2.50 & 24.80 \\
DBH $(\mathrm{cm})$ & 1189 & 10.85 & 2.47 & 2.98 & 17.85 \\
Height $(\mathrm{m})$ & 1189 & 0.0765 & 0.0509 & 0.0011 & 0.3647 \\
Volume IB $\left(\mathrm{m}^{3}\right)$ & 1189 & 0.0911 & 0.0597 & 0.0014 & 0.4128 \\
Volume OB $\left(\mathrm{m}^{3}\right)$ & & & & & \\
\hline
\end{tabular}

ent stands. These groups of measurements may violate the basic assumption of independence, as multiple observations from a single sampling unit may be highly correlated (Gregoire 1987). To address the problem of autocorrelation within a plot, researchers have used the mixed-effects modelling technique (Sharma and Parton 2007; Subedi and Sharma 2011) or correlation structure (Diéguez-Aranda et al. 2006), or both (Subedi and Sharma 2013). Details about mixed-effects modelling are provided by Vonesh and Chinchilli (1997) and Pinheiro and Bates (2000).

In this study, stem volumes were calculated at an individual tree scale. Therefore, the data have a three-level hierarchical structure. Trees are nested within plots and plots within plantations. As a result, two random effects parameters were introduced

where, $\quad V=$ total volume (inside or outside bark, $\mathrm{m}^{3}$ ) $D=$ diameter at breast height $(\mathrm{DBH} ; \mathrm{m})$ $H=$ total tree height $(\mathrm{m})$

$\beta$ and $\gamma$ are parameters to be estimated and $\varepsilon$ is the error term.

Eq. (1) assumes that $\mathrm{V}=0$ when $\mathrm{D}=0$. Therefore, this model is more appropriate for calculating volume above breast height. In practice, however, total volume estimates are preferred. For this, Eq. (1) can be modified by adding a constant (parameter), $\alpha$, to the right-hand side of the model to ensure that $\mathrm{V}$ equals the volume accumulated before the tree reaches breast height, i.e.,

$$
V=\alpha+\beta D^{\gamma} H^{3-\gamma}+\varepsilon
$$

Other models considered in this study were two widely used volume models: the combined variable volume model (Spurr 1952) and the modified combined variable volume model (Schumacher and Hall 1933). The mathematical expression for the combined variable volume model is:

$$
V=\alpha+\beta D^{2} \mathrm{H}+\varepsilon
$$

Similarly, the modified combined variable volume model has the following form:

$$
V=\beta D^{\gamma} H^{\delta}+\varepsilon
$$

where, $\delta$ is a parameter to be estimated and all other variables are as defined earlier. An intercept was added to the right-hand side of this model to ensure non-zero volume when $\mathrm{D}=0$.

$$
V=\alpha+\beta D^{\gamma} H^{\delta}+\varepsilon
$$

The intercept in all three volume models, Eqs. (2), (3) and (5), should be greater than zero $(\alpha>0)$ to ensure the inside and outside bark volumes are positive and greater than zero.

Data used in developing volume models frequently contain measurements from multiple trees from a given sample plot although individual plots are generally located in differ- to all three volume models to address the variances at plot and plantation levels. These models with random effects can be written as:

(6)

$$
\begin{aligned}
& V_{i j k}=\alpha+b_{i}+b_{i j}+\beta D_{i j k}{ }^{\gamma} H_{i j k}^{3-\gamma}+\varepsilon_{i j k} \\
& V_{i j k}=\alpha+b_{i}+b_{i j}+\beta D_{i j k}{ }^{2} H_{i j k}+\varepsilon_{i j k} \\
& V_{i j k}=\alpha+b_{i}+b_{i j}+\beta D_{i j k}{ }^{\gamma} H_{i j k}{ }^{\delta}+\varepsilon_{i j k}
\end{aligned}
$$

where $V_{i j k}$ is the stem volume of tree $k(k=1,2, \ldots 16)$, plot $j$ $(j=1,2$, and 3$)$, and plantation $i(i=1,2, \ldots 25)$ with dbh and total height as $D_{i j k}$ and $H_{i j k}$, respectively. Random effects $b_{i}$ and $b_{i j}$ are normally distributed with mean zero and variances $\sigma_{s}^{2}$ and $\sigma_{p}^{2}$, respectively (i.e., $b_{i} \sim N\left(0, \sigma_{s}^{2}\right)$ and $b_{i j} \sim N(0$, $\left.\sigma_{p}^{2}\right)$ ). Similarly, $\varepsilon_{i j k}$ is normally distributed with mean zero and variance $\sigma_{e}^{2}$ (i.e., $\varepsilon_{i j k} \sim N\left(0, \sigma_{e}^{2}\right)$ ). In the case of heteroscedasticity, $\sigma_{e}^{2}$ will be multiplied by a variance function. Other variables are as defined earlier.

Eqs. (6), (7), and (8) were fitted to the data set using the mixed-effects modelling approach of SAS Institute Inc. (2015). Parameters and fit statistics, (pseudo $\mathrm{R}^{2}$, MSE, AIC (Akaike 1978), and -2 log likelihood), were estimated and inspected for the inconsistencies mentioned earlier. To check - predicted), for volume were calculated for all trees using the models and plotted against the predicted volumes. If present, the heteroscedasticity problem can be resolved by specifying a variance function (Pinheiro and Bates 2000) in each model. Two variance functions, exponential and power, were considered in this study. The variance function resulting in a smaller value of AIC was selected to account for heteroscedasticity in the data for each model.

The final model for estimating volumes for jack pine and black spruce plantations was selected based on fit statistics, (highest pseudo $\mathrm{R}^{2}$, lowest MSE, AIC and -2 log likelihood), and logical consistency. To examine whether the outside bark volume is always greater than the inside bark, outside and inside bark volumes were estimated using outside and inside bark volume models, respectively, for all trees from all 25 plantations for both species. The ratio of outside bark to possible heteroscedasticity, estimates of residuals, (observed 
Table 2. Fit statistics for Eqs. (6), (7), and (8) without random effects for jack pine and black spruce. $\left(R^{2}=\right.$ coefficient of determination, MSE = mean square error, AIC = Akaike's Information Criteria, and LL = log likelihood]

\begin{tabular}{|c|c|c|c|c|c|c|c|c|}
\hline Model & Pseudo $\mathrm{R}^{2}$ & MSE & AIC & $-2 \mathrm{LL}$ & Pseudo $\mathrm{R}^{2}$ & MSE & AIC & $-2 \mathrm{LL}$ \\
\hline \multicolumn{4}{|c|}{ Jack pine outside bark } & & \multicolumn{4}{|c|}{ Jack pine inside bark } \\
\hline 6 & 0.9589 & 0.0892 & -2063 & -2073 & 0.98007 & 0.2316 & -6877 & -6887 \\
\hline 7 & 0.9565 & 0.1840 & -2034 & -2042 & 0.9785 & 0.2731 & -6789 & -6797 \\
\hline \multirow[t]{2}{*}{8} & 0.9592 & 0.1047 & -2068 & -2080 & 0.9803 & 0.2722 & -6905 & -6917 \\
\hline & \multicolumn{4}{|c|}{ Black spruce outside bark } & \multicolumn{4}{|c|}{ Black spruce inside bark } \\
\hline 6 & 0.9635 & 0.001170 & -7362 & -7372 & 0.9886 & 0.2734 & -9882 & -9892 \\
\hline 7 & 0.9634 & 0.001218 & -7350 & -7360 & 0.9880 & 0.3973 & -9873 & -9881 \\
\hline 8 & 0.9636 & 0.001222 & -7363 & -7375 & 0.9886 & 0.3174 & -9894 & -9906 \\
\hline
\end{tabular}

inside bark volumes was then calculated for each tree for each species and plotted against inside bark volumes.

Finally, inside bark volumes were calculated using the taper models developed for these species (Sharma and Parton 2009). Average bias in estimating inside bark volumes by $\mathrm{DBH}$ and height classes were calculated for both species for the taper models and the final volume models developed here. The bias resulting from volume models was compared to its counterpart from taper models to examine the predictive accuracy of tree volume models.

\section{Results and discussion}

Eqs. (2), (3), and (5), without random effects, were first fit to the data using the NLMIXED procedure of the SAS Institute Inc. (2015). However, in the regression, convergence was a problem for all models. Several unsuccessful attempts were made to fit the models by changing the initial parameter values. Therefore, models were fit by changing the DBH unit from $\mathrm{cm}$ to $\mathrm{m}$ for both inside and outside bark volumes for both species. This solved the convergence problem. Eqs. (6), (7), and (8) were then fit to the data by including random effects one at a time starting at $b_{i}$. All models converged but none of the random effects, plantation $\left(b_{i}\right)$ or plot $\left(b_{i j}\right)$ was significant. This resulted in increased AIC and -2 log likelihood values. The models were then fit to the data by including both random effects. None of the random effects was significant in regressions for all models for both inside and outside bark volumes for both species. Moreover, including both random effects further increased the AIC and $-2 \mathrm{log}$ likelihood values of all models for both species. Therefore, all inside and outside bark volume models were fit for further analysis without random effects.

Residual plots, (plotted against predicted volumes), showed some heteroscedasticity in the data set (not shown here) for all models. Therefore, Eqs. (6), (7), and (8) were fit to the data with a power and exponential variance function separately. For both inside and outside bark volume models for both species, the variance function with a power to DBH resulted in better fits, (smaller AIC values), than the exponential function for all models. Therefore, the power function was selected as the variance function. The power function was significant in the regression and reduced the AIC values significantly for all models.
For fit statistics, pseudo $\mathrm{R}^{2}$ values were very similar for all models. (Table 2). All other statistics (MSE, AIC and -2 log likelihood) were higher for Eq. (7) than for Eqs. (6) and (8). The MSE was lower for Eq. (6) than for Eq. (8) for both inside and outside bark volumes. However, AIC and -2 log likelihood values were slightly lower for Eq. (8) than for Eq. (6).

The estimates for intercept $(\alpha)$ for Eqs. (6) and (7) were significant and greater than zero for both inside and outside bark volumes for both species. However, these estimates for Eq. (8) were negative except for outside bark volume for black spruce which was not significant in the regression. This was not expected as the intercept is interpreted as the average value of total volume accumulated by a tree until it reaches breast height (i.e., total volume when DBH is zero and total height is $1.3 \mathrm{~m}$ ). As mentioned earlier, for a logistically consistent volume model, the intercept should be significant and greater than zero.

Attempts were made to fit Eq. (8) by forcing the intercept to be greater than zero. This resulted in an estimate of $\alpha$ that was less than $1 \times 10^{-8} \mathrm{~m}^{3}$ for both inside and outside bark volumes for both species. This estimate is too small for a tree with $1.3 \mathrm{~m}$ height. Moreover, it was not significant in the regression for both inside and outside bark volumes for both species. While Eq. (7) had logically consistent parameter estimates, its fit statistics were inferior to those for Eq. (6). Therefore, Eq. (6) was selected and analyzed further for logical consistency and predictive accuracy. Eq. (6) without random effects and the variance as a power function of $\mathrm{DBH}$ can be written as:

$$
V_{i}=\alpha+\beta D_{i}^{\gamma} H_{i}^{3-\gamma}+\varepsilon_{i}
$$

where, $V_{i}$ is the volume of the $i$ th tree with $\mathrm{dbh} D_{i}$ and height $H_{i}, \varepsilon_{i}$ is normally distributed with mean zero and variance $\sigma_{e}^{2} D_{i}^{\varphi}\left(\right.$ i.e., $\left.\epsilon_{i} \sim N\left(0, \sigma_{e}^{2} D_{i}^{\varphi}\right)\right)$ and $\varphi$ is a parameter to be estimated. Other parameters are as defined earlier.

Estimates for parameters along with fit statistics for Eq. (9) are presented in Table 3. As mentioned earlier, both intercepts (inside and outside bark volumes) were significant and greater than zero for both species. All other parameters were consistent in terms of sign and magnitude across the species and volume model. The weight (power of DBH) was positive for both inside and outside volume models for both species. 
Table 3. Parameter estimates (standard error in parenthesis) and fit statistics (MSE, mean square error, AIC, Akaike's Information Criteria, and LL, log likelihood) of Eq. (9) fitted to inside bark and outside bark volume data using NLMIXED procedure for jack pine and black spruce plantations in boreal Ontario

\begin{tabular}{|c|c|c|c|c|}
\hline \multirow[b]{2}{*}{ Parameters } & \multicolumn{2}{|c|}{ jack pine } & \multicolumn{2}{|c|}{ black spruce } \\
\hline & Inside bark & Outside bark & Inside bark & Outside bark \\
\hline$a$ & $0.002397(.0005)$ & $0.007942(.0020)$ & $0.00037(0.00004)$ & $0.0040(0.0005)$ \\
\hline$\beta$ & $0.2245(0.0134)$ & $0.1779(0.0269)$ & $0.2846(0.0147)$ & $0.3241(0.0366)$ \\
\hline$\gamma$ & $1.9023(0.0136)$ & $1.8313(0.0355)$ & $1.9614(0.0117) 1$ & $.9614(0.0261)$ \\
\hline$\varphi^{*}$ & $4.1524(0.1675)$ & $3.1687(0.3637)$ & $4.8677(0.1325)$ & $1.1377(0.1006)$ \\
\hline MSE & 0.2316 & 0.0892 & 0.2734 & 0.0012 \\
\hline AIC & -6877 & -2063 & -9882 & -7362 \\
\hline$-2 \mathrm{LL}$ & -6887 & -2073 & -9892 & -7372 \\
\hline
\end{tabular}

*Weight, power of DBH (m)

Table 4. Mean bias (observed - predicted) of the residuals from inside bark volume model (Eq. 9) and taper models by Sharma and Parton (2009) for jack pine and black spruce plantations in Ontario, Canada

\begin{tabular}{lcccc}
\hline $\begin{array}{l}\text { Diameter and } \\
\text { height classes }\end{array}$ & & $\begin{array}{c}\text { Number } \\
\text { of trees }\end{array}$ & Eq. (9) & $\begin{array}{c}\text { Taper } \\
\text { model }\end{array}$ \\
\hline Jack pine & & & & \\
\hline Diameter & $<10.0$ & 38 & -0.0010 & 0.0033 \\
class (cm) & $10.1-15.0$ & 326 & 0.0012 & 0.0043 \\
& $15.1-20.0$ & 486 & 0.0012 & 0.0038 \\
& $20.1-25.0$ & 225 & -0.0018 & -0.0012 \\
& $>25.0$ & 60 & -0.0024 & -0.0278 \\
& & & & \\
Height & $<10.0$ & 10 & -0.0021 & 0.0068 \\
class (m) & $10.1-15.0$ & 497 & 0.0019 & 0.0032 \\
& $15.1-20.0$ & 588 & -0.0017 & 0.0001 \\
& $>20.0$ & 40 & -0.0040 & -0.0076 \\
\hline Black spruce & & & & \\
\hline Diameter & $<5.0$ & 11 & -0.0001 & -0.0002 \\
class (cm) & $5.1-10.0$ & 214 & 0.0001 & -0.0003 \\
& $10.1-15.0$ & 558 & 0.0003 & 0.0010 \\
& $15.1-20.0$ & 371 & -0.0006 & 0.0031 \\
& $>20.0$ & 35 & -0.0072 & -0.0002 \\
& & & & \\
Height & $<5.0$ & 7 & 0.0000 & -0.0001 \\
class (m) & $5.1-10.0$ & 439 & 0.0003 & -0.0003 \\
& $10.1-15.0$ & 683 & -0.0003 & 0.0022 \\
& $>15.0$ & 60 & -0.0008 & 0.0047 \\
\hline
\end{tabular}

The AIC values were reduced significantly by introducing the weight into both volume models for both species.

To check whether outside bark volume exceeded inside bark for all trees, the ratio of outside to inside was plotted against inside bark volumes (Fig. 2). The ratio is greater than 1.06 and 1.16 for jack pine and black spruce, respectively. This confirms that the estimated outside bark volume exceeds the inside bark volume for all trees for both species.
It is also clear from these figures that black spruce, in general, has thicker bark than jack pine.

Finally, model accuracy was checked by comparing the bias resulting from the volume model, Eq. (9), to that produced by taper models (Table 4). The biases for volume and taper models are very similar for all DBH and height classes. Overall, bias was smaller for Eq. (9) than for the taper model for both DBH and height classes for both species. This confirms that the estimated inside bark volumes using inside bark volume models are as good as, or even more accurate, than those obtained using taper models.

The volume model presented here was originally developed by Sharma and Oderwald (2001) using a dimensional analysis approach. Since their model did not contain an intercept, it could be applied to any system of unit, imperial or metric, using the same values of estimated parameters. However, the intercept differed significantly from zero and was positive for both inside and outside bark volume models for both species in this study. Therefore, to apply these models to data in another system of measurement, the estimated values of the intercepts need to be converted accordingly. Similarly, the units of measurement for all variables need to be in the same derived units (e.g., volume in cubic feet and height and $\mathrm{DBH}$ in feet).

For example, the estimated value of the intercept for jack pine inside bark volume model is 0.002397 in cubic metres. To apply this in the imperial system where volume is in cubic feet, this number needs to be converted to cubic feet (0.084649), and both DBH and height should be in feet, not inches. No change is needed in the values of the estimates for the other parameters. These remain the same for all systems of units.

\section{Conclusions}

Development of forest management plans requires accurate estimates of tree volume using tree volume models or taper models. Both tree volume and taper models require the values of DBH and total height to generate tree volume. If only the entire stem volume is of interest, tree volume models are simpler to use. However, calculating tree volume using taper models requires integrating taper over tree height. Tree volume estimates may be given as inside or outside bark, depending on the purpose of this information, where inside bark volumes are less than outside bark volumes for a given tree. Therefore, for logical consistency, outside bark volume estimated using a tree volume model should always exceed inside bark volume. Similarly, all these volumes should be greater than zero, regardless of tree size.

Logically consistent inside and outside bark volume models were developed for jack pine and black spruce plantations. Three volume models, a modified form of dimensionally compatible, a combined variable, and a modified combined variable, were fitted to data from northern Ontario. A non- 
Jack pine

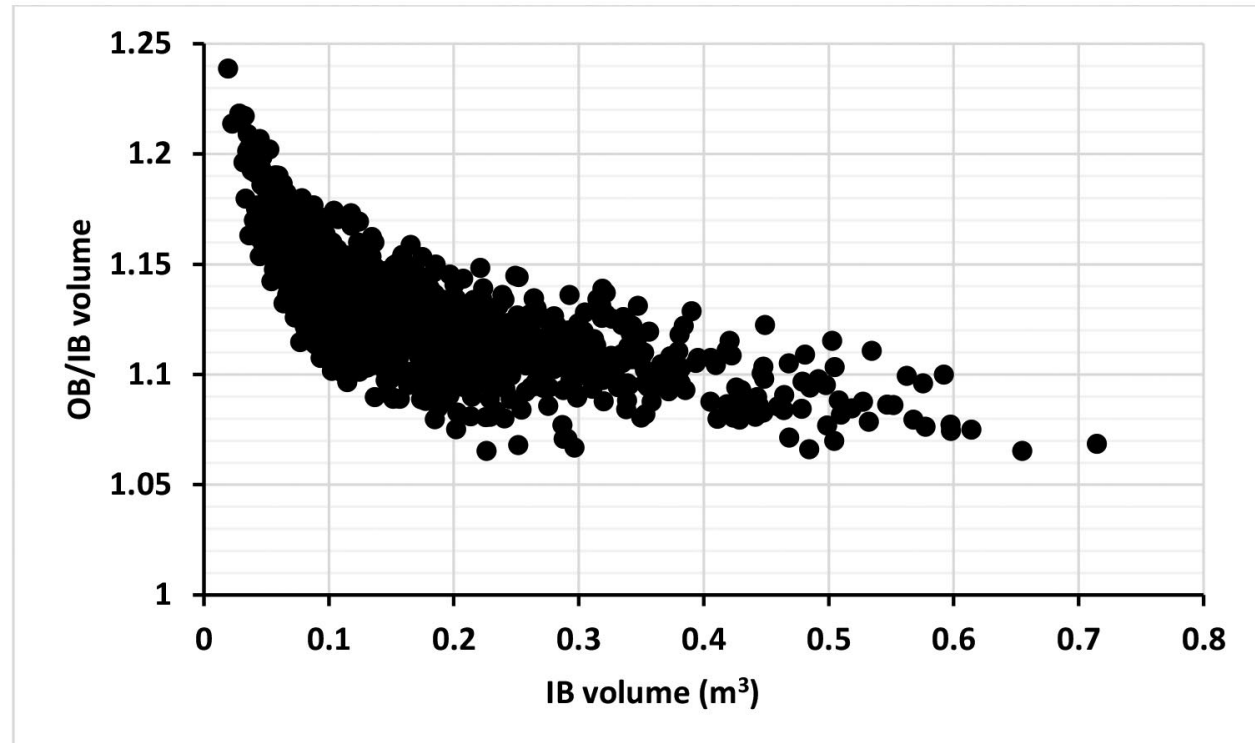

Black spruce

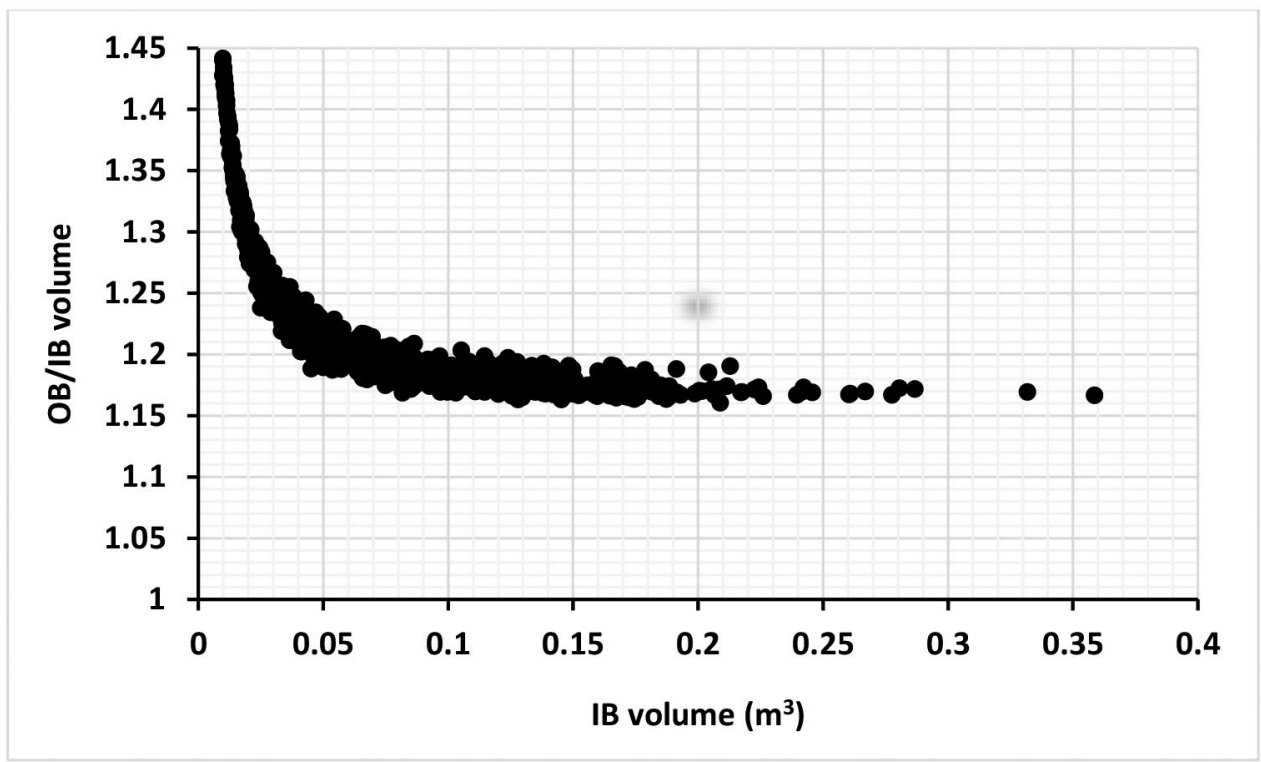

Fig. 2 Scatterplots of the ratio of outside bark (OB) to inside bark (IB) volumes estimated using Eq. (9) against inside bark volumes for jack pine and black spruce 
linear mixed-effects modelling approach was applied in fitting the models. Since trees were nested within plots and plots were nested within plantations, two random effects at plantation and plot levels were introduced. Similarly, a weight (power function) was used to address heteroscedasticity in the data. While random effects were not significant in the regression analyses, the weight was significant.

The combined variable volume model was logically consistent but fit statistics were inferior to those of the other two models. However, the modified combined variable volume model was logically inconsistent, as the estimated intercept was negative or non-significant in the regression. Therefore, the modified form of dimensionally compatible volume model was selected for both species. This model is logically consistent, as the estimated inside and outside volumes are greater than zero and the outside bark volume exceeds the inside bark volume for all trees of both species. This model can be used to estimate inside and outside bark volumes of jack pine and black spruce plantations in boreal forests. Since the model was developed using dimensional analysis, it can be applied with any system of units by changing the estimate for the intercept to match the system of units and using the same units for diameter and total height.

\section{Acknowledgements}

This study was supported by the Ontario Ministry of Natural Resources and Forestry. The author is grateful to Lisa Buse (OFRI) for editing an earlier version of the manuscript, John Parton (OMNRF) for coordinating the data collection work, and the anonymous reviewers and associate editor for their constructive and insightful review comments.

\section{References}

Akaike, H. 1978. A Bayesian analysis of the minimum AIC procedure. Ann. Inst. Stat. Math. 30: 9-14.

Avery, T.E. and H.E. Burkhart. 2002. Forest Measurements. McGraw-Hill, New York, NY. 456 Pp.

Diéguez-Aranda, U., H.E. Burkhart and R.L. Amateis. 2006. Dynamic site model for loblolly pine (Pinus taeda L.) plantations in the United States. For. Sci. 52: 262-272.
Gregoire, T.G. 1987. Generalized error structure for forestry yield models. For. Sci. 33: 423-444.

OMNRF. (2016). [Ontario Ministry of Natural Resources and Forestry]. State of Ontario's Natural Resources - Forests 2016. Ontario Ministry of Natural Resources and Forestry, Sault Ste. Marie, ON. [https://www.ontario.ca/page/state-ontarios-naturalresources-forests-2016, accessed April 5, 2019].

Pinheiro J.C. and D.M. Bates. 2000. Mixed-Effects Models in S and S-PLUS. Springer-Verlag. New York, NY. 528 p.

SAS Institute Inc. 2015. SAS Institute Inc. Cary, NC.

Schlesinger, W.H. 1991. Biogeochemistry: An Analysis of Global Change. Academic Press, New York, NY. 688 p.

Schumacher, F.X. and F.S. Hall. 1933. Logarithmic expression of timber-tree volume. J. Agric. Res. 47: 719-734.

Sharma, M. and R.G. Oderwald. 2001. Dimensionally compatible volume and taper models. Can. J. For. Res. 31: 797-803.

Sharma, M. and J. Parton. 2007. Height-diameter models for boreal tree species in Ontario using a mixed-effects modeling approach. For. Ecol. Manage. 249:187-198.

Sharma, M. and J. Parton. 2009. Modeling stand density effects on taper for jack pine and black spruce plantations using dimensional analysis. For. Sci. 55: 268-282.

Sharma, M., R.G. Oderwald and R.L. Amateis. 2002. A consistent system of models for tree and stand volume. For. Ecol. Manage. 165: 183-191.

Spurr, S. 1952. Forest Inventory. The Ronald Press Company, New York. $476 \mathrm{p}$.

Statutes of Ontario. 1995. Crown Forest Sustainability Act, revised. R.S.O. 1998. Chapter 25 and Ontario Regulation 167/95.

Subedi, N. and M. Sharma. 2011. Individual-tree diameter growth model for black spruce and jack pine plantations in northern Ontario. For. Ecol. Manage. 261: 2140-2148.

Subedi, N. and M. Sharma. 2013. Climate-diameter growth relationships of black spruce and jack pine trees in boreal Ontario, Canada. Global Change Biol. 19: 505-516.

Vonesh, E.F. and V.M. Chinchilli. 1997. Linear and Nonlinear Models for the Analysis of Repeated Measurements. Marcel Dekker Inc., New York, NY. 560 p. 